\title{
La milpa como centro de origen
}

\section{The Maize as a Center of Origin}

\section{A roça de milho como lugar de origem}

Zuiri Méndez-Benavides

Socióloga

Universidad Nacional

Costa Rica

Recibido: 20/11/2017 Aceptado: 18/2/2018

\section{Resumen}

"El Maíz no es una cosa, es un centro de origen", es una frase que surgió en la Red en Defensa del Maíz en México, que cuenta de un compilado de saberes colectivos de los pueblos indígenas y campesinos en lucha por la defensa de las semillas criollas de maíz contra los transgénicos. El presente ensayo reflexiona sobre el caso costarricense, pero no pierde de vista el ámbito mayor latinoamericano.

Palabras clave: Soberanía alimentaria, maíz, transgénicos, luchas indígenas, América Latina, Costa Rica, derechos humanos.

\section{Abstract \\ "The Maize is not a thing, it is a center of origin" is amotto that emerged in the Red}

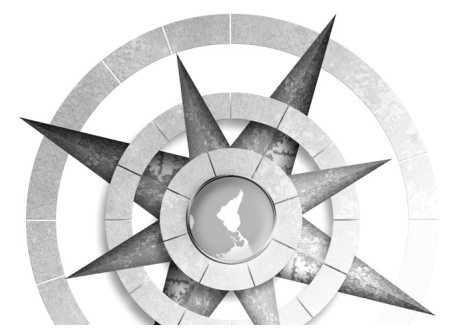

DOI: https://doi.org/10.15359/tdna.34-63.7 en Defensa del Maíz [Network in Defense of Maize] in Mexico. This phrase gives an account of a compilation of collective knowledge of the indigenous peoples and peasants in struggle for the defense of the criollo or native seeds of corn against the GMOs. This essay reflects on the Costa Rican case, but it does not lose sight of the greater Latin American scope.

Keywords: Food sovereignty, corn, transgenic, indigenours struggles, Latin America, Costa Rica, human rights

\section{Resumo}

"O milho não é uma coisa, é um centro de origem", é uma frase que surgiu na Rede em Defesa do Milho no México. Esta frase dá conta de uma compilação do conhecimento coletivo dos povos indígenas e camponeses na luta pela defesa das sementes de milho criollo contra os transgênicos. Este ensaio reflete sobre o caso da Costa Rica, mas não perde de vista o maior alcance latino-americano.

Palavras chave: Soberania alimentar, milho, transgênicos, lutas indígenas, América Latina, Costa Rica, dereitos humanos 


\section{El maíz es un centro ${ }^{1}$. La meseta}

En el barrio, las casas están apretadas, secas, silenciosas. La gente sale con su auto, regresa con su auto, entra al parqueo del supermercado, se pasea por pasillos con temperatura controlada, toma lo que "necesita", paga en la caja, regresa al auto, pasa al restaurante de comida rápida, regresa al auto, al tráfico, regresa al garaje.

La cocina de esas casas, aunque todavía sea parte de ese espacio de encuentro ancestral donde la conversación de historias y la mezcla de alimentos es una magia, se convierte ahora, en un espacio de despensa de productos procesados, envueltos en plástico, refinados, conservados, enlatados, tostados, congelados. Los alimentos que comeremos, comprados en ese supermercado $-\mathrm{O}$ en el mejor caso comprado en la pulpería del barrio- fueron pasteurizados, esterilizados, radicidiados, radurizados. Se les añadió sal, azúcar, glicerol, glutamato monosódico, solutos,

1 Es la Red en Defensa del Maíz, que en México inició el nombrar el maíz como un centro de origen. Gran parte de las ideas de este texto son producto de las reflexiones de comunidades indígenas y campesinas compiladas por GRAIN y ETC. Estas palabras son un homenaje al trabajo en la tierra y a los saberes compartidos para cuidar tantas comunidades y territorios que en Latinoamérica se encuentran en permanente defensa. sulfitos, nitritos, sorbatos, benzoatos, parabenos e incluso antibióticos.

En la mesa del desayuno, almuerzo, café o cena, se sirve parte de la identidad de "la meseta central costarricense": un jugo Dos Pinos, una tostada de pan Bimbo, un huevo de Pipasa (empresa comprada por Cargill), arroz y frijoles del gallo pinto ${ }^{2}$ -importados de Centroamérica-.

Las milpas que algunas vez vimos cuando éramos niñas, fueron convertidas en residenciales, centros comerciales y carreteras. El maíz, en el mejor de los casos, lo encontramos en una tortilla emplasticada, de marcas comerciales como Tortirricas o en la bolsa de Maseca para preparar los tamales de fin de año.

La comida es un centro de haceres, pero también es parte de la comunidad imaginada que constituye una identidad nacional o un nacionalismo. Como dice el investigador mexicano José Luis Juárez (2018), la comida es también un territorio conformado por sentidos y símbolos mediante los cuales las comunidades crean y reproducen sus identidades.

2 Pinto: hace referencia al gallo pinto, platillo hecho a base de arroz y frijoles guisados que se consumen tradicionalmente a la hora del desayuno en Costa Rica.

\section{La milpa como centro de origen Zuiri Méndez-Benavides}


Las identidades nacionales, como concepto que transmuta en el tiempo, producen y reproducen prácticas e ideologías. Los patrones de alimentación en la meseta central de Costa Rica representan parte de esa construcción de nacionalismos en una larga historia que comprende la invasión española, que luego convergió en Estados nación liberales y ahora se configura desde los Estados neoliberales.

Los nacionalismos hegemónicos tienen que ver con los sistemas alimentarios, en tanto son productos también de una construcción en movimiento. Según el investigador Rafael Cuevas Molina (2005), el nacionalismo tico que fue construido por sectores liberales se impuso desde arriba tomando como referencia modelos eurocéntricos de una copia que nunca pudieron ser. ¿Quiénes somos los pueblos latinoamericanos en medio de la relación entre identidad y alimentación?

Pues así como se quiso blanquear la piel, el pensamiento y las espiritualidades de los pueblos indígenas, afrodescendientes y orientales -ahora diversos habitando el continente latinoamericano-; así también se quiso blanquear la comida. Sustituir los múltiples colores de las mazorcas por el trigo blanco, cambiar las tortillas negras por un pan blanco y los atoles azules por el arroz blanco.

El maíz dentro de la milpa corre la suerte que Darcy Ribeiro nos comparte al explicar que somos pueblos americanizados, unidos por el despojo, la pobreza, la dependencia y el subdesarrollo, por un lado, y la riqueza, el poder y el desarrollo, por otro. La comida manifiesta en su conformación esta disputa.

Los siglos pasaron y la profundización de tecnologías y técnicas europeas se fue imponiendo a los pueblos mestizos que desplazaron los cultivos de maíz, las milpas. Los españoles drenaron el gran lago de Texcoco, secando el agua que sostenía una compleja red de chinampas o chinamitl, huertas flotantes rodeadas por cañas, constantemente húmedas donde se podían cultivar múltiples especies comestibles.

A pesar de las imposiciones, el sistema colonial no pudo prohibir el cultivo del maíz, pero sí logró introducir en muchos espacios el consumo de nuevos productos. Durante la época de las independencias -y la creación de lo que fue mejor visto para comer-, reprodujo patrones alimenticios europeos o norteamericanos, en la importación de semillas, recetas y patrones de consumo.

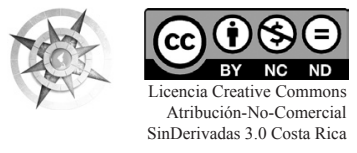


A mediados del siglo XIX inició en el planeta la expansión de la Revolución Verde, que en palabras de Verónica Villa, promovió la agroindustria:

[...] como la producción (no solo de alimentos), mediante métodos más sofisticados (no necesariamente más eficientes) en grandes extensiones de terreno para cosechar grandes volúmenes y obtener mucha ganancia a toda costa. Pero en el fondo, en obediencia a su ser industrial, se perpetra una violencia, incluso extrema, a todos los procesos naturales, a todos los ciclos vitales implícitos desde que se cultiva, hasta la siembra... e implica una violencia llamada integración vertical, que consta de agregarle valor económico a los alimentos con más y más procesos: de la tierra acaparada a la semilla certificada, al suelo, a su fertilización y desinfección mega química, a la mecanización agrícola, al transporte, al lavado, al procesamiento, empaque, estibado, almacenado y nuevo transporte (incluso internacional) hasta arribar a mercados, estanquillos, supermercados y comedores públicos (2012: pág. 17)

A este sistema encadenado de producción y consumo, se sumó la privatización y expansión de los límites de lo antes comercializable. En Costa Rica, Silvia Rodríguez demuestra cómo con el apoyo de Estados
Unidos y el financiamiento de la Fundación Rockefeller, se impulsaron programas en Latinoamérica para el "mejoramiento" genético orientado a la producción de semillas híbridas.

Junto a este proceso, el Banco Mundial y la FAO impulsaron la certificación para las variedades modernizadas de semillas para su comercialización. Estas políticas, como los programas de fitomejoramiento fueron desplazando las variedades locales, hasta convertir las semillas en mercancías externas a los sistemas de intercambio campesino o indígena.

Y no es porque la búsqueda de datos sea la única forma de demostrar que la milpa diversa, compleja, colectiva, se ha ido monoculturizando. Las organizaciones campesinas e indígenas desde la Red de Mujeres Rurales de Costa Rica, hasta el MST de Brasil, nos lo confirman en sus denuncias, mientras mantienen y recuperan prácticas que buscan proteger las diversidades culturales que hacen de la alimentación un centro de autonomía para poblaciones indígenas y campesinas.

El centro de investigaciones GRAIN identifica que en tres décadas que van de 1960 a 1990, la venta de fertilizantes en Latinoamérica creció un 8\%, 
pero la producción agrícola creció menos de un 4\%. Recuentan que al mismo tiempo, empresas como Nestlé, Dow Chemical, Bayer, Merck, Unilevel crecieron a tasas mucho más elevadas que las de cualquier agricultura del mundo. Las corporaciones, en ese sentido, dictan los nuevos patrones de sistemas alimentarios que los Estados deben producir, integrando patrones de consumo, incluso a las estructuras de identidad nacional, sin lograr garantizar la alimentación de toda la población.

Este embate contra la alimentación campesina e indígena, contra la forma de la agricultura de los pueblos, responde a ese común que nos une como pueblos latinoamericanos, a ese hilo histórico que Darcy Ribeiro plantea:

¿Acaso no son todos ustedes descendientes de la matriz indígena?, ¿Los resultantes de la colonización ibérica?, ¿Los que se emanciparon en el curso de un mismo movimiento de descolonización?, ¿Los que, después de independientes, hipotecaron sus países, sin distinción, a los banqueros ingleses?, ¿Los que fueron y están siendo recolonizados por las corporaciones norteamericanas? (1978: 13).

En los últimos veinte años, la siembra del maíz descendió en Costa
Rica un $74 \%$. El maíz actualmente representa el 10\% de la dieta de granos básicos en Costa Rica, que junto al resto de la comida recibe fumigación con 18.2 kilos de agrotóxicos al año. Actualmente, la identidad de la meseta central está moldeada por la comida aséptica que sostiene la más grande cadena global de comercio agroindustrial. En ese contexto, el maíz desaparece de nuestra dieta.

Pero, a pesar de que vivimos en una identidad nacional hegemónica, donde lo que crece o nace de la tierra queda encerrado en un proceso basado en tecnologías adecuadas a la velocidad de la acumulación de capitales, sabemos que en las periferias prácticas y simbólicas, se mantiene la resistencia de un otro posible sistema alimentario.

\section{La periferia}

En el barrio, la milpa crece gloriosa, los olores, las plantas medicinales, el ayote, los frijoles junto a ella. El maíz pujagua $^{3}$ de esta cosecha se convirtió en masa, tanelas ${ }^{4}$, bizcochos, atole, pinolillo, chicheme ${ }^{5}$, chicha y

3 Variedad de maíz de color morado que se cultiva tradicionalmente en las provincias de Guanacaste y Puntarenas, en el Pacífico costarricense.

4 Pan preparado con maíz, quesos y panela propio de la región de Guanacaste.

5 Atol fermentado a partir de maíz que se prepara generalmente en Guanacaste.

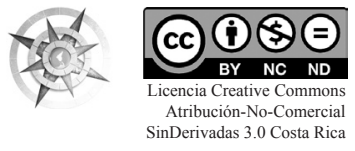


picadillos. El horno de barro y leña se enciende, suenan las palmadas de la tortilla.

En el mercado de Santa Cruz de Guanacaste, en la cocina de una campesina que forma parte de la lucha por la recuperación de tierras de Medio Queso, en la frontera con Nicaragua, en el fogón de esa familia en Meleruk, del territorio indígena Bribri de Talamanca, en el Caribe sur, el maíz se muele, se seca, se nixtamaliza, se fermenta, se cuida la semilla. La periferia puede estar en todas partes.

En Costa Rica existen entre 80 y 100 variedades de maíz criollo, y según datos del INEC son destinadas 17.756 hectáreas a la producción de maíz, de las cuales 12 mil se dedican al autoconsumo y 10 mil fueron sembradas con semillas propias. El maíz es un centro de origen, lo dicen los pueblos de México que se organizaron en la Red en Defensa del Maíz contra la imposición de las semillas transgénicas.

Según investigaciones de GRAIN, es fundamental comprender que las poblaciones campesinas son las creadoras y diversificadoras de todos y cada uno de los cultivos que hoy disfrutamos como humanidad; cada una de esas personas, junto a los saberes de las otras, fueron quienes llevaron a cabo el largo, paciente y delicado proceso de convertir malezas y hierbas en alimento abundante, sabroso, nutritivo y atractivo.

El maíz, descendiente del teozintle, fue domesticado hace más de $10 \mathrm{mil}$ años por poblaciones ancestrales que habitaban lo que luego se llamaría América. Pueblos latinoamericanos, descendientes de esta semilla que se propagó por todo el continente.

Las sociedades que vivían en Abya Yala, antes de que llegaran los invasores ibéricos, tenían su propio modo de producción. La milpa no es solo un cultivo solitario de maíz, también es de ayote, quelites, frijoles. Ya lo han dicho cientos de pueblos en este continente, que la milpa es una conversación de reciprocidades.

El maíz, intrínsecamente ligado al saber del manejo del agua, fue producto de un conjunto de técnicas especializadas que fue centro alimenticio de las culturas mexica, maya e inca (como imperios o lo que Darcy Ribeiro considera como civilizaciones). Pero también lo fue de muchos pueblos que no fueron imperios, que desarrollaron tecnologías precisas para su sobrevivencia y que su grandeza recae en el pequeño impacto que generaron en los ecosistemas que les rodearon. 
La polinización abierta, bien común de todo el planeta, hace de todas las semillas y las semillas de maíz un bien que no debe privatizarse de ninguna manera. En cada nueva semilla que nace, interviene la cultura humana, como también los insectos, el aire, las geografías.

En las periferias de Costa Rica nacen los pueblos, retoños de granos de maíces de tantos nombres aún sin registrar, que conviven con las selvas, las lluvias, la humedad y minerales de montañas ancestrales como las de Talamanca. El pueblo bribri y cabecar son Ditsöwö: que quiere decir descendientes del maíz que Sibö y Sulá compartieron.

Luis Vitale, historiador chileno, señala que de 10 mil años que tiene la humanidad de existir, un $98 \%$ de ese tiempo transcurrido representó a una humanidad que comprendió que podía relacionarse de manera armoniosa con la naturaleza, sin acabarla ni destruirla por completo.

Las culturas ancestrales tenían sus propios modos de producción, autarquías de saberes complejos y precisos que sabían y saben leer los biorritmos del planeta. Verónica Villa narra que la agricultura es lo que los campesinos y pueblos indígenas hacen:
"[...] a como dé lugar, porque es vital sembrar y cuidar el ciclo completo, vasto y entretejido del crecimiento de los varios cultivos (hermanos entre sí o diversos pero complementarios), el sol o lluvia, limpieza y abono; plantar, cosechar y guardar, que le da sentido a todo lo que se vive, sobre todo si es en familia y en comunidad". (Villa, 2012: pág. 17)

La agricultura es la cultura de cultivar la tierra, es semilla y raíz de las más viejas tecnologías que la humanidad todavía utiliza en el cuido y compartir de las semillas criollas, en la creatividad de las mezclas para preparar alimentos con lo que se dispone alrededor. La milpa es la manifestación de esas relaciones históricas, su producción y reproducción existe antes de las naciones, de los Estados nación.

\section{El centro de origen}

No sé si será posible imaginarnos milpas sembradas encima de edificios, ferias comunitarias de comidas caseras en los barrios, alimentos creciendo entre los barrotes de las cárceles casas -seguridad autoimpuesta- de la cultura meseteña del hogar.

Las culturas del cuido de la tierra continúan creando, a pesar del cercamiento de sus bienes comunes, a

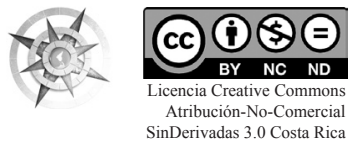


pesar de identidades hegemónicas del producto empaquetado y de la comida importada.

Gracias a la presión que ejerció el gran movimiento social por la defensa del maíz criollo y la caminata nacional contra el maíz transgénico, el 25 de julio del 2014 el gobierno de Costa Rica decretó el maíz como Patrimonio Cultural por su herencia gastronómica que incluye tradiciones, prácticas agroculturales, usos, saberes, sabores y colores asociados al grano.

Sin embargo, al mismo tiempo, desde el Ministerio de Agricultura se siguen concesionando permisos de importación de agrovenenos, autorizaciones para la expansión del monocultivo de la piña, de la palma africana, y promoción de una ley de semillas para prohibir las semillas criollas. Continúa la idea de un nacionalismo donde la comida provenga de relaciones privativas, desconectada de solidaridades, gestionada por corporaciones.

En un mismo pequeño país, meseta y periferia, continúan espacios en contradicción, movimientos que traen memoria, historia, de experiencias que cada persona contiene desde los sistemas alimentarios vividos. Un cruce de veredas.

Ramón Vera en El libro de los Saberes dice que somos como una constelación, cada persona como un rincón de experiencia que a su vez es un centro, unido a más centros. Un centro que solo es posible junto a los demás. Como la milpa, como alguien que vive una experiencia urbana, como una mujer indígena cosecha una mazorca morada. Yo creo que construimos esos rincones para hacerlos centros, a pesar de todos los embates por separarnos, por fragmentarnos, por hacernos olvidar.

El maíz como mezcla, diversidad y posibilidad de reinvención. La milpa como conversación que nos recuerda que es posible la convivencia. Las semillas que nos dicen que lo que no se mueve, se muere. Hay un centro en las periferias que en silencio sigue cultivando la tierra.

San José, noviembre 2017 


\section{Referencias bibliográficas}

Cuevas, Rafael y Mora, Andrés. (2015). Buscando el futuro. Crisis civilizatoria y posneoliberalismo en América Latina. San José: EUNED.

GRAIN. La agricultura: sus saberes y cuidados. En Andares et al. (2016). El libro de los saberes. México: Planetaria.

La Nación. (25/7/2014). Decretan el maíz como patrimonio cultural de Costa Rica. Enlace: http://www. nacion.com/el-pais/patrimonio/ decretan-al-maiz-como-patrimonio-cultural-de-costa-rica/QZHD4MULNVAC7P5JDFG2LXSUWQ/ story/

Ribeiro, Darcy. (1978). La cultura latinoamericana. México: UNAM.

Rodríguez, Silvia. (2017). Guía para semilleros y semilleras. San José: Red de Semilleros y Semilleras y Red en Coordinación en Biodiversidad.
Villa, Verónica et al. (2012) ¿Matar la agricultura? México: COA-CASIFOP, ITACA.

Villa, Verónica et al. (ed.). (2012). El maíz no es una cosa, es un centro de origen. México: COA, CASIFOP, ITACA.

Vitale, Luis. (1983). Hacia una historia del ambiente en América Latina. De las culturas aborígenes a la crisis ecológica actual. México: Nueva Sociedad Editorial Nueva Imagen.

Yankelevich, Pablo. Sobre el libro de José Luis Juárez López (2008). Nacionalismo culinario. La cocina mexicana del siglo XX. México: Conaculta. Enlace: http:// www.scielo.org.mx/scielo.php?pi$\mathrm{d}=\mathrm{S} 1607050 \times 2010000300013 \&$ \&cript=sci_arttext 